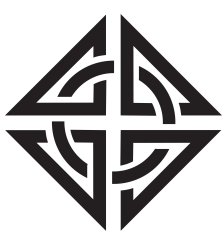

SCIENTIA
Sharif University of Technology

Scientia Iranica

Transactions F: Nanotechnology

www.scientiairanica.com

\title{
Preference of nanoporous graphene to Single-Walled Carbon Nanotube (SWCNT) for preparing silica nanohybrid Pickering emulsion for potential Chemical Enhanced Oil Recovery (C-EOR)
}

\author{
M. AfzaliTabar ${ }^{a}$, M. Alaei ${ }^{b, *}$, R. Ranjineh Khojasteh ${ }^{a}$, F. Motiee ${ }^{a}$ and \\ A.M. Rashidi ${ }^{\mathrm{b}}$ \\ a. Department of Chemistry, Islamic Azad University, North Tehran Branch, Tehran, P.O. Box 1913674711, Iran. \\ b. Nanotechnology Research Center, Research Institute of Petroleum Industry (RIPI), Tehran, P.O. Box 14665-1998, Iran. \\ Received 8 August 2016; received in revised form 7 December 2016; accepted 6 March 2017
}

\section{KEYWORDS \\ Pickering emulsion; \\ Nanohybrid; \\ Chemical Enhanced \\ Oil Recovery \\ (C-EOR); \\ Silica; \\ Carbon nanotube.}

\begin{abstract}
We prepared nanoporous graphene/silica nanohybrid and demonstrated its better Pickering emulsion properties for Chemical Enhanced Oil Recovery in comparison to the similar silica nanohybrid with a single-walled carbon nanotube. The samples were characterized with X-Ray Diffraction (XRD), Field Emission Scanning Electron Microscopy (FE-SEM), and Thermal Gravimetry Analysis (TGA). Emulsion phase morphology was investigated with optical microscopic image. Evaluation results demonstrated that the best samples are $70 \%$ nanoporous graphene $/ \mathrm{SiO}_{2}$ (both methods) and $70 \% \mathrm{SWCNT} / \mathrm{SiO}_{2}$ nanohybrid (Method 1). Contact angle measurement results showed that $70 \%$ nanoporous graphene/ $\mathrm{SiO}_{2}$ nanohybrid (Method 2) is more effective in the improvement of the stone reservoir wettability alteration from oil-wet to water-wet. Interfacial tension results indicate that the maximum amount is related to the injection of water, and the minimum amount is related to the injection of nanofluid of $70 \%$ nanoporous graphene $/ \mathrm{SiO}_{2}$ nanohybrid (Method 2). This result indicates the preference of $70 \%$ nanoporous graphene $/ \mathrm{SiO}_{2}$ nanohybrid (Method 2) for decreasing the interfacial tension in comparison to the other samples.

(C) 2017 Sharif University of Technology. All rights reserved.
\end{abstract}

\section{Introduction}

Emulsions stabilized by solid particles have been known for more than a century and named after S. Pickering who discovered that coalescence of droplets is

\footnotetext{
*. Corresponding author. Tel.: +9821 48255053;

Fax: +982144739696

E-mail addresses: m.afzali.t89@gmail.com ( $M$.

AfzaliTabar); alaiem@ripi.ir (M. Alaei);

r_ranjinehkhojasteh@iau-tnb.ac.ir (R. Ranjineh Khojasteh);

f_motiee@iau-tnb.ac.ir (F. Motiee); rashidiam@ripi.ir (A.M. Rashidi)
}

doi: $10.24200 /$ sci. 2017.4428 suppressed when solid particles are adsorbed at the oil-water interface [1]. Applications of solid-stabilized emulsions in various fields have been described in several articles and patents. Depending on whether the particles are more hydrophilic or hydrophobic, they tend to stabilize oil-in-water or water-in-oil emulsions, respectively [2]. Surface wettability and particle size are two important parameters of controlling emulsion properties. The amphiphobic nature of pristine SWCNTs and carbon pushes them toward accumulation at the water/oil interface preferentially, instead of dispersing in any of the bulk phases. At the same time, silica particles have been extensively studied for oil-inwater Pickering emulsions as hydrophilic emulsifiers [3]. 
Therefore, we anticipate that the SWCNT-silica combination offers a unique structure that can offer great flexibility in controlling the surface wettability by adjusting the carbon/silica ratio. Thus, it is possible to modify the distributions of partitioning coefficients between oil and water [4].

Graphene is a monolayer of carbon atoms arranged in hexagonal lattice $[5,6]$. It has excellent optical, mechanical, and electronic properties [7-13]. Graphene oxide can be formed with the oxidation of graphene $[14,15]$. The process of oxidation causes the dispersion of GO sheets in water and other polar solvents because of the functional groups formation (such as carboxyl, epoxy, and hydroxyl) in the edges [16]. Therefore, GO has an amphiphile surface with hydrophilic edges and hydrophobic plane [17]. In addition, GO has many applications such as catalytic supports for chemical reactions [18,19], adsorption [20,21], and separation of pollutants [22].

In this research, we have successfully prepared nanoporous graphene silica nanohybrid and demonstrated its better Pickering emulsion properties for Chemical Enhanced Oil Recovery (C-EOR) in comparison to the similar silica nanohybrid with a SingleWalled Carbon Nanotube (SWCNT). Stability of the Pickering emulsions was controlled for one month. Emulsion phase morphology was investigated by optical microscopic image. Evaluation results demonstrated that the best samples are $70 \%$ nanoporous graphene $/ \mathrm{SiO}_{2}$ nanohybrids (both methods). Stability of the selected nanohybrids was investigated by alteration of salinity, $\mathrm{pH}$, and temperature. Moreover, results showed that the related Pickering emulsions of the selected nanohybrids have very good stability at $1 \%$ salinity, moderate and high $\left(25^{\circ} \mathrm{C}\right.$ and $\left.90^{\circ} \mathrm{C}\right)$ temperatures, and neutral and alkaline $(7,10) \mathrm{pH}$ that are suitable for the oil reservoirs conditions. However, contact angle and interfacial tension measurement results showed that the $70 \%$ nanoporous graphene $/ \mathrm{SiO}_{2}$ nanohybrid (Method 2) is more effective in improvement of the stone reservoir wettability alteration from oil-wet to water-wet and can decrease the interfacial tension. Therefore, $70 \%$ nanoporous graphene/ $\mathrm{SiO}_{2}$ nanohybrid (Method 2) Pickering emulsion can be used for Chemical Enhanced Oil Recovery (C-EOR).

\section{Materials and methods}

Nanoporous graphene and SWCNT were supplied by Nanotechnology Research Center of Research Institute of Petroleum Industry (RIPI). Commercial sodium silicate solution $\left(\mathrm{SiO}_{2} / \mathrm{Na}_{2} \mathrm{O}=3.35\right)$ was used as the precursor to form the silica structure. Sodium dodecyl benzene sulfonic acid (SDBS), 2-Propanol, and $n$-octane were used as received from Merck Company without any further purification.
The as-prepared nanohybrids were characterized by Field Emission Scanning Electron Microscope (FESEM) using a Holland Phillips XL30 microscope. XRD patterns of the samples were recorded in ambient air using a Holland Philips X-ray powder diffraction $(\mathrm{Cu}$ $\mathrm{K}_{\alpha}, \lambda=1.5406 \AA$ ) at scanning speed of $2^{\circ} / \mathrm{min}$ from $20^{\circ}$ to $80^{\circ}$. Transmission Electron Microscopy (TEM) was performed with a Philips EM 208 FEG instrument operating at $90 \mathrm{kV}$. Optical microscopic images were prepared with Quantimet-570 microscope.

\subsection{Functionalization of carbon nanostructures}

Carbon nanostructures were acid treated with concentrated $\mathrm{HNO}_{3}$. Therefore, $2 \mathrm{~g}$ of carbon nanostructures were added to a mixture of about $160 \mathrm{ml}$ distilled water and $140 \mathrm{ml}$ nitric acid and allowed to reflux for $10 \mathrm{~h}$. After filtration and neutralization with distilled water, the sample dried in the oven at $60^{\circ} \mathrm{C}$.

\subsection{Synthesis of carbon nanostructures/silica nanohybrid}

2.2.1. Method 1: Addition of the carbon nanostructure in media before starting the synthesis of silica nanoparticles

Suitable amount of the functionalized carbon nanostructure for 70,50 , and $10 \mathrm{wt} \%$ nanohybrids was dispersed in $30 \mathrm{ml}$ of $\mathrm{HCl}(2.5 \%)$ solution at room temperature. Then, 2-3 ml sodium silicate was added. After about 5 hours of mixing, the solution was washed with distilled water and dried in an oven at $60^{\circ} \mathrm{C}$.

\subsubsection{Method 2: Addition of the carbon nanostructure among silica nanoparticles synthesis steps}

A quantity of $2-3 \mathrm{ml}$ sodium silicate was first dissolved in $30 \mathrm{ml}$ of $\mathrm{HCl} 2.5 \%$ at room temperature. Then, the suitable amount of the functionalized carbon nanostructure for 70, 50, and $10 \mathrm{wt} \%$ nanohybrids was dispersed in $30 \mathrm{ml}$ of $\mathrm{HCl}(2.5 \%)$ solution at room temperature. After about 5 hours of mixing, the solution was washed with distilled water and dried in the oven at $60^{\circ} \mathrm{C}$.

\subsection{Preparation of Pickering emulsions}

A quantity of $0.05 \mathrm{~g}$ nanohybrid was dissolved in $50 \mathrm{ml}$ distilled water and then sonicated for 10 minutes in ultrasonic bath. After that, $0.15 \mathrm{~g}$ of SDBS, $3 \mathrm{ml} 2-$ propanol, and $3 \mathrm{ml} n$-decane as oil model were added to the solution, respectively. Then, it was sonicated for 10 minutes again. The Pickering emulsions' stability of these nanohybrids was investigated for one month.

\section{Results and discussion}

\subsection{Modification of carbon nanostructure}

Depending on the hydrophilicity, the nanofluid can form $\mathrm{O} / \mathrm{W}$ or $\mathrm{W} / \mathrm{O}$ emulsion in reservoir condition. 


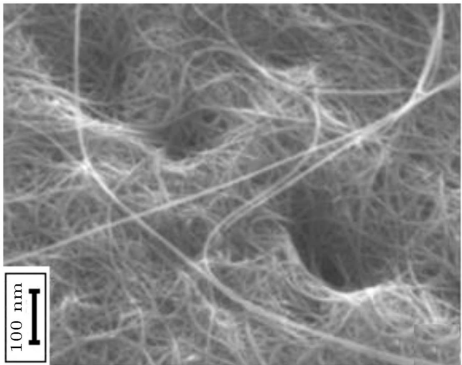

(a)

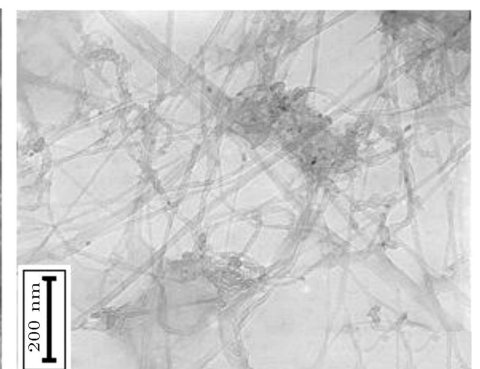

(b)

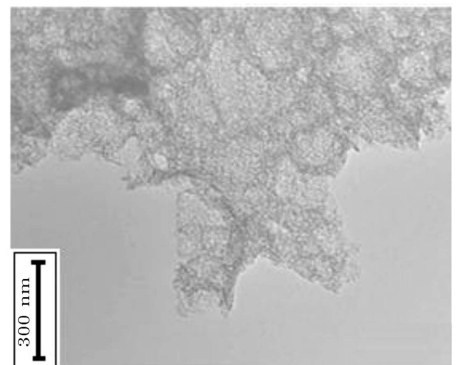

(c)

Figure 1. (a) SEM, and (b) TEM images of SWCNT, and (c) TEM image of nanoporous graphene received from Research Institute of Petroleum Industry (RIPI).

Therefore, carbon nanostructure was modified with nitric acid to enhance its hydrophilicity for producing $\mathrm{O} / \mathrm{W}$ emulsion. The generation of oxygenated groups on the carbon nanostructure surface is directly related to the time of treatment with $\mathrm{HNO}_{3}$. Presumably, these groups reside at the tube ends and also on the sidewalls, bonded to sp3-like carbons in regions of increased curvature on the graphitic sheet (e.g., alcohols). SEM and TEM images of SWCNT and TEM images of nanoporous graphene received from Research Institute of Petroleum Industry (RIPI) are demonstrated in Figure 1(a), (b), and (c), respectively. Obviously, the nanotube structure can be seen for SWCNT in this figure. In addition, the layer structure of graphene can be seen in Figure 1(c).

\subsection{Synthesis of carbon nanostructures/silica nanohybrids}

Selection of the as-prepared nanohybrids for XRD, SEM, and TGA analyses is done with special attention paid to the related emulsion stability. XRD patterns of nanoporous graphene, silica nanoparticles, $70 \%$ nanoporous graphene/ $\mathrm{SiO}_{2}$ nanohybrid (Method 1), $70 \%$ nanoporous graphene $/ \mathrm{SiO}_{2}$ nanohybrid (Method 2 ), and $70 \%$ SWCNT $/ \mathrm{SiO}_{2}$ nanohybrid (Method 1) are shown in Figure 2(a)-(e), respectively. The characteristic peak of nanoporous graphene is about $29.08^{\circ}$ that is observed in Figure 2(a), indicating the existence of nanoporous graphene with a single or a few layers [23]. According to Figure 2(b), silica nanoparticles have amorphous structures [24]. $70 \%$ nanoporous graphene/ $\mathrm{SiO}_{2}$ nanohybrid (Method 1), $70 \%$ nanoporous graphene $/ \mathrm{SiO}_{2}$ nanohybrid (Method 2 ), and $70 \%$ SWCNT $/ \mathrm{SiO}_{2}$ nanohybrid have amorphous structures.

The morphologies of the as-prepared nanohybrids were investigated by SEM images. Figure 3 demonstrates the SEM images of nanoporous graphene; $70 \%$ SWCNT $/ \mathrm{SiO}_{2}$ nanohybrid (Method 1) and $70 \%$ nanoporous graphene $/ \mathrm{SiO}_{2}$ (Methods 1 and 2) nanohy-

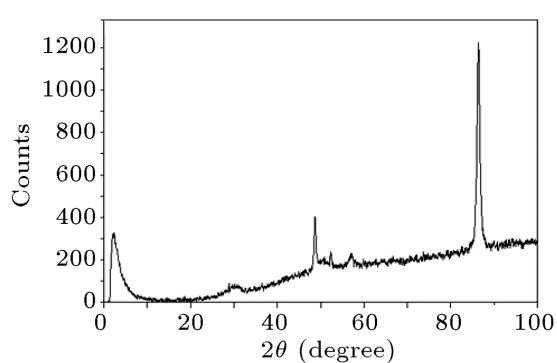

(a) Nanoporous graphene

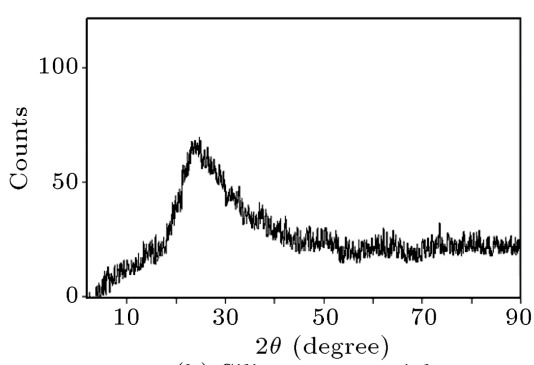

(b) Silica nanoparticle

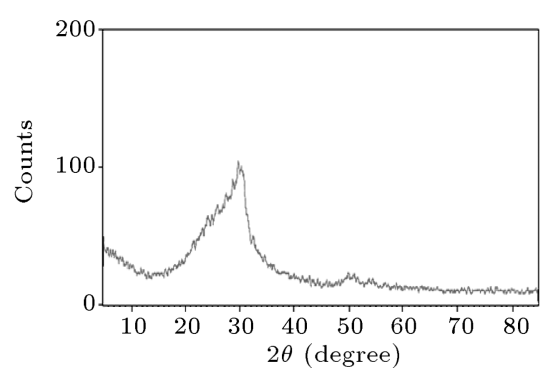

(c) $70 \%$ graphene/silica-Method 1

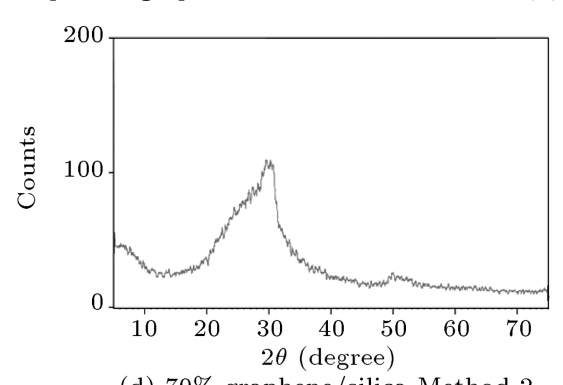

(d) $70 \%$ graphene/silica-Method 2

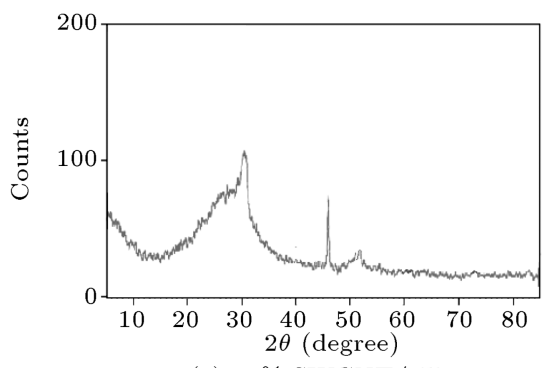

(e) $70 \% \mathrm{SWCNT} /$ silica

Figure 2. XRD patterns of (a) nanoporous graphene, (b) silica nanoparticles, (c) $70 \%$ nanoporous graphene $/ \mathrm{SiO}_{2}$ nanohybrid (Method 1), (d) $70 \%$ nano porous graphene/ $\mathrm{SiO}_{2}$ nanohybrid (Method 2), and (e) $70 \% \mathrm{SWCNT} / \mathrm{SiO}_{2}$ nanohybrid (Method 1). 


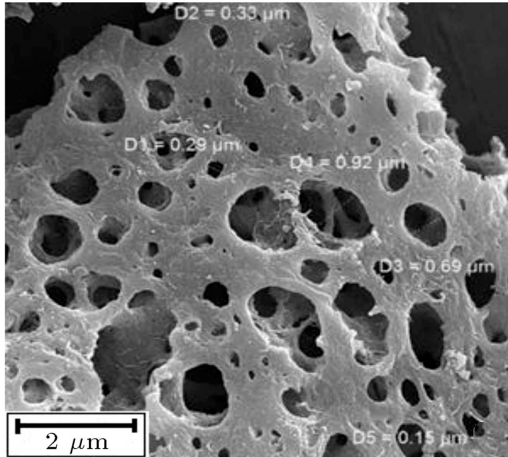

(a)

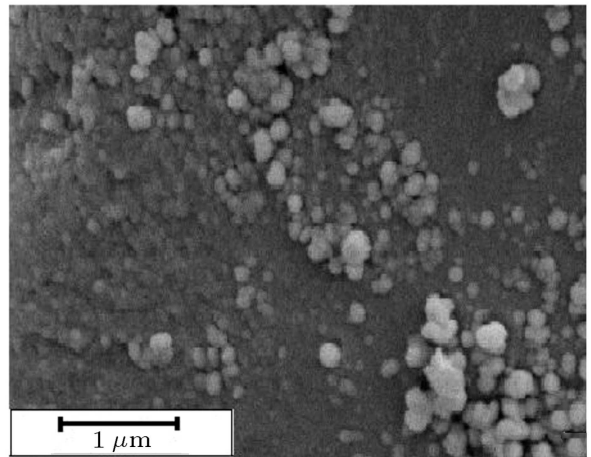

(c)

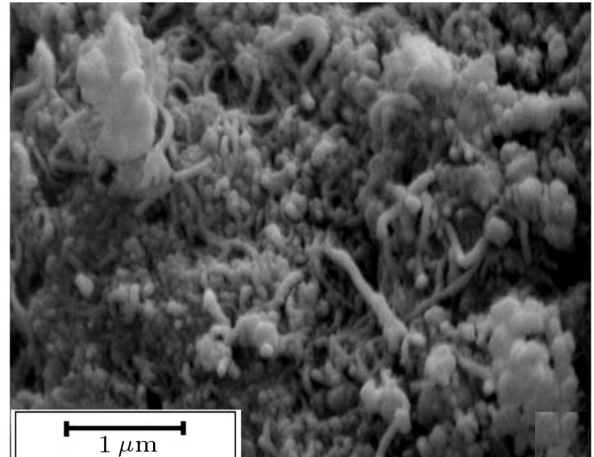

(b)

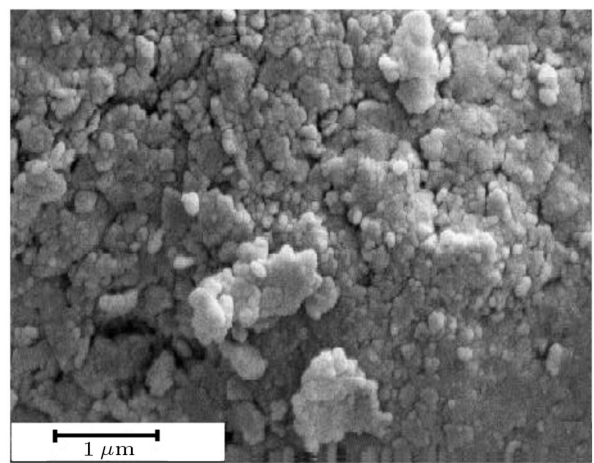

(d)

Figure 3. SEM images of (a) nanoporous graphene, (b) $70 \%$ SWCNT $/ \mathrm{SiO}_{2}$ nanohybrid (Method 1), (c) $70 \%$ nanoporous graphene/ $\mathrm{SiO}_{2}$ (Method 1), and (d) $70 \%$ nanoporous graphene/ $\mathrm{SiO}_{2}$ (Method 2).

brid are presented in Figure 3(a)-(d), respectively. The layer and nanoporous structure of the graphene sample can be observed in Figure 3(a). In addition, in Figure 3(b), the tubular structure of SWCNT is presented. In Figure 3(c), (d) and (e), we can see the silica nanoparticles with spherical morphology that were uniformly attached to the related nano carbon structure.

Thermal Gravimetric Analysis (TGA) results of $70 \%$ nanoporous graphene $/ \mathrm{SiO}_{2}$ nanohybrid and $70 \%$ SWCNT $/ \mathrm{SiO}_{2}$ nanohybrid in Nitrogen atmosphere with $0.1^{\circ} \mathrm{C} / \mathrm{min}$ temperature rate increase are presented in Figure 4. As can be seen, $\mathrm{H}_{2} \mathrm{O}$ molecules escaped from the samples at $100^{\circ} \mathrm{C}$. nanoporous graphene has high thermal stability [25]; therefore, it was degraded at about $600^{\circ} \mathrm{C}$, but SWCNT was degraded at about $260-270^{\circ} \mathrm{C} . \mathrm{SiO}_{2}$ nanoparticles remain stable even at $800^{\circ} \mathrm{C}$ because of their high thermal stability.

Nanohybrids were prepared by the addition of carbon compound during the preparation of silica nanoparticles by sol-gel method using two different mixing methods:

- Method 1: Addition of the carbon compound in media before starting the synthesis of silica nanoparticles;

- Method 2: Addition of the carbon compound during the silica nanoparticles synthesis steps.

Evaluation of the nanohybrids Pickering emul-
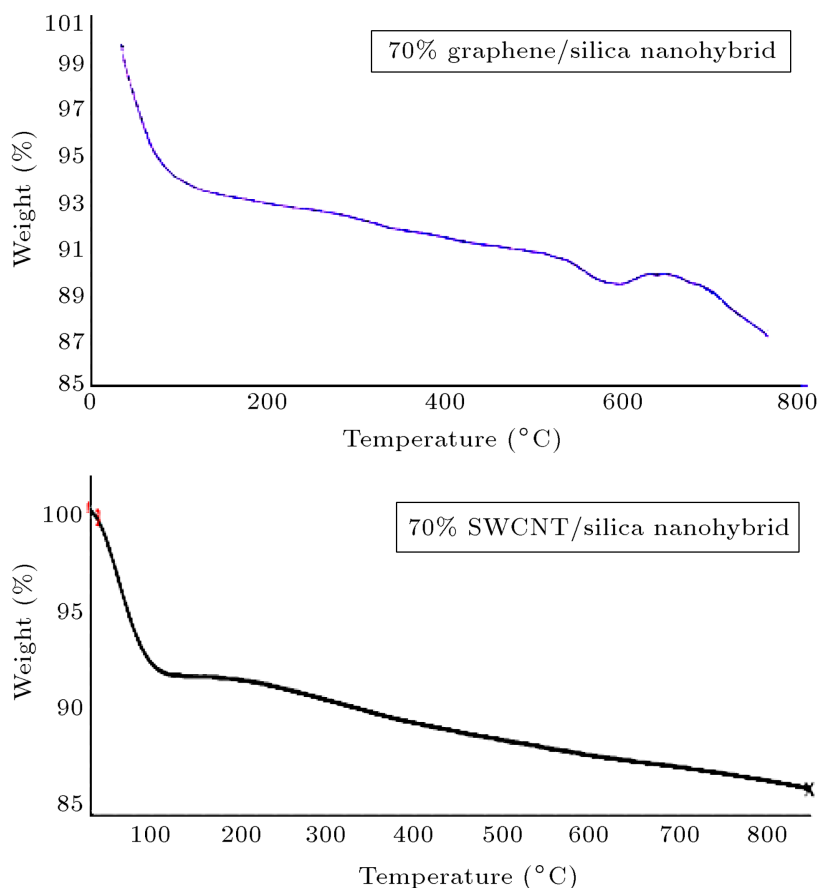

Figure 4. Thermal Gravimeteric Analysis (TGA) results of $70 \%$ nanoporous graphene/ $\mathrm{SiO}_{2}$ nanohybrid and $70 \%$ $\mathrm{SWCNT} / \mathrm{SiO}_{2}$ nanohybrid.

sions stability was performed for one month, and the related images are shown in Figure 5. Figure 5(a) and (b) show the stability of nanoporous graphene/silica and 


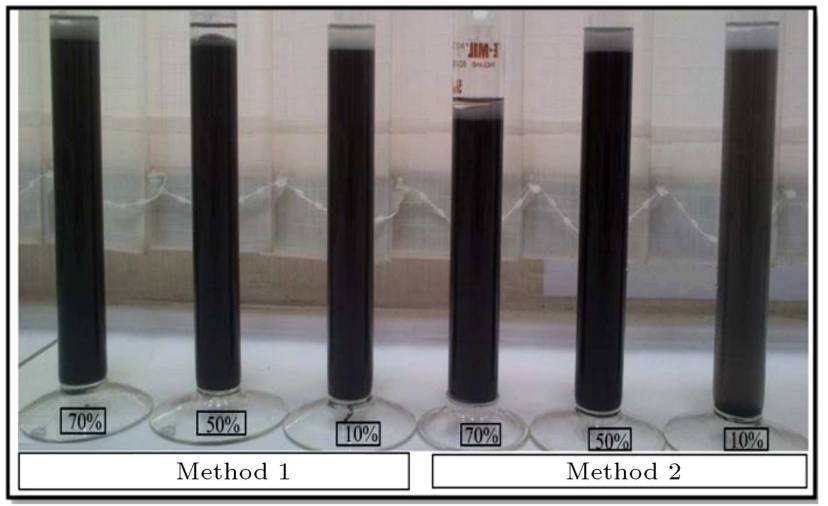

(a)

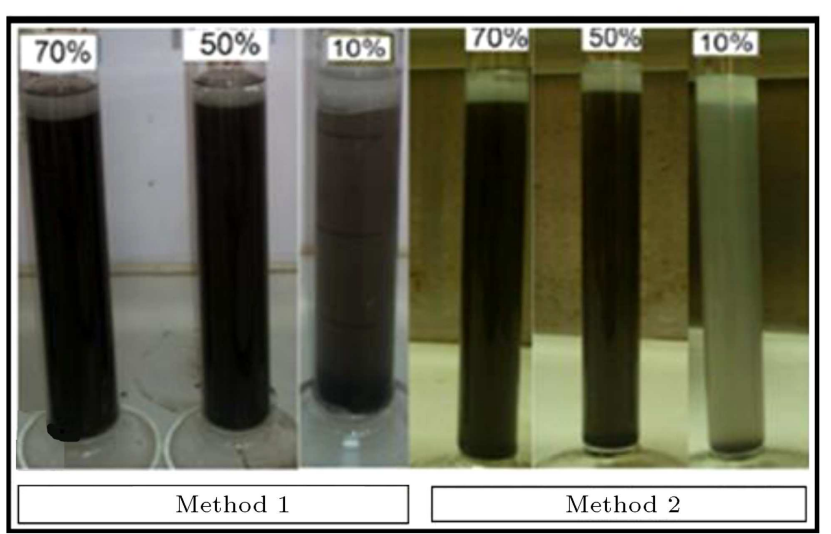

(b)

Figure 5. Evaluation of the nanohybrids Pickering emulsion stability for one month: (a) Nanoporous graphene/ $\mathrm{SiO}_{2}$ Pickering emulsions and (b) SWCNT/ $/ \mathrm{SiO}_{2}$ nanohybrid Pickering emulsions.

SWCNT/silica nanohybrid Pickering emulsions made by two different methods after a month, respectively.

The comparison between emulsion stability of nanoporous graphene/silica nanohybrids is shown in Figure 5(a). As can be seen, 70\% nanoporous graphene $/ \mathrm{SiO}_{2}$ Pickering emulsions that were prepared with Methods 1 and 2 have lower precipitation than the others do. The comparison between emulsion stability of SWCNT/silica nanohybrids is shown in Figure 5(b). As can be seen, $70 \%$ and $50 \%$ SWCNT $/ \mathrm{SiO}_{2}$ nanohybrid emulsions that were prepared with Method 1 have the lowest precipitation in comparison to the others. Therefore, Pickering emulsions of $70 \%$ nanoporous graphene $/ \mathrm{SiO}_{2}$ nanohybrids (both methods) and $70 \%$ and $50 \% \mathrm{SWCNT} / \mathrm{SiO}_{2}$ nanohybrid (Method 1) have the best stability in comparison to the other samples.

Optical microscopic images of the nanohybrids Pickering emulsions are shown in Figure 6. According to the suitable optical microscopic images of such Pickering emulsions that can be used for C-EOR (reported by Professor Resasco [3]), the images in Figure 6 were investigated. A suitable Pickering emulsion has homogenous dispersion of emulsion droplets with good

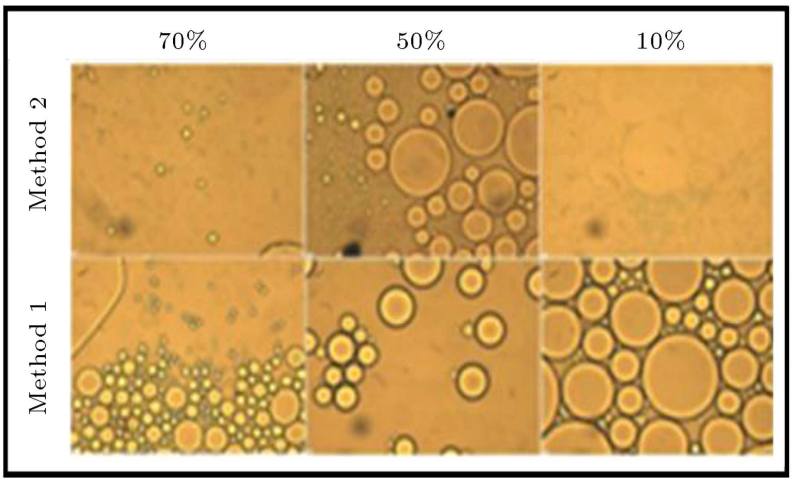

(a)

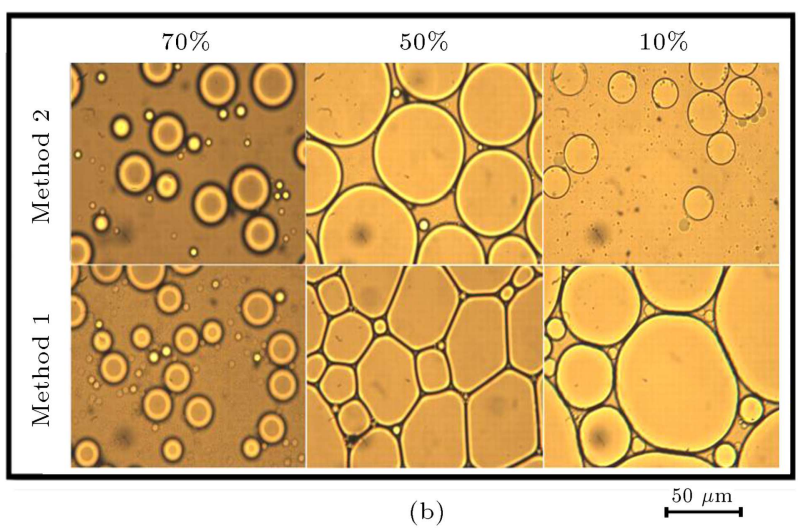

Figure 6. Emulsion phase optical microscopic images of (a) SWCNT/ $\mathrm{SiO}_{2}$ nanohybrid Pickering emulsions and (b) nanoporous graphene nanohybrid Pickering emulsions.

compact, where the solid particles of nanohybrids are surrounded by them. By considering the evaluation of emulsion stability (presented in Figure 5), 70\% $\mathrm{SWCNT} / \mathrm{SiO}_{2}$ nanohybrid emulsion (Method 1) and $70 \%$ nanoporous graphene $/ \mathrm{SiO}_{2}$ nanohybrid emulsions (both methods) were selected (Figure 6(a) and (b), respectively). The mentioned Pickering emulsions have uniform emulsion droplet size and dispersion, and each of droplets is surrounded very well with solid particles of the related nanohybrid [26,27].

For the evaluation of the as-prepared nanohybrids ability for decreasing interfacial tension and wettability improvement of carbonate reservoir rock and judgment about their application for chemical enhanced oil recovery, contact angle and interfacial tension of the related nanofluids were evaluated. The mentioned evaluations were performed according to the methods presented in reference [24] with slight modification.

Figure 7 shows the nanofluid contact angle measurement of $70 \%$ nanoporous graphene $/ \mathrm{SiO}_{2}$ nanohybrids (both methods) and $70 \% \mathrm{SWCNT} / \mathrm{SiO}_{2}$ nanohybrid. For measuring contact angle, the chamber is full of kerosene and water droplet, or a nanofluid droplet is injected by a syringe. In this condition, a contact angle below and over $90^{\circ}$ represents more hydrophilic and hydrophobic samples, respectively. According to 


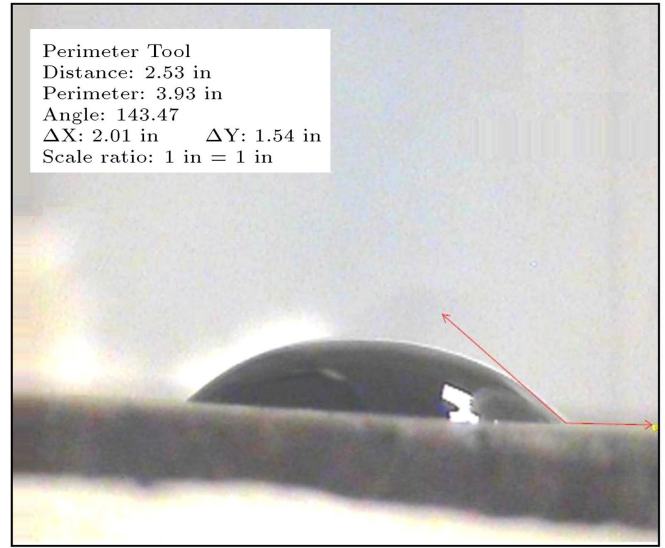

(a)

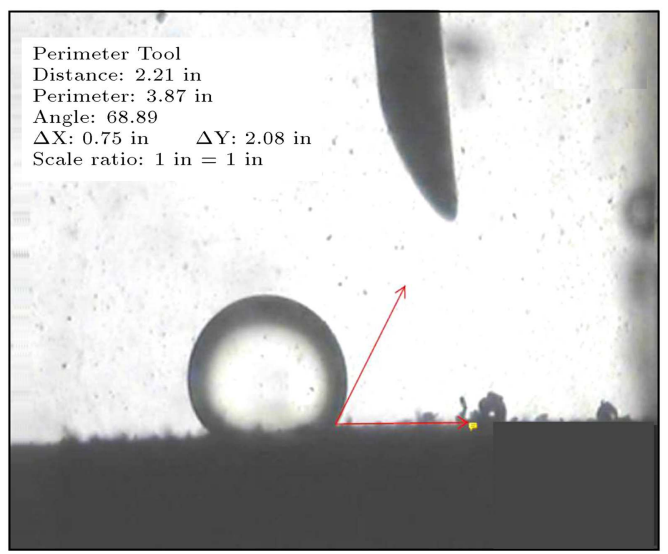

(c)

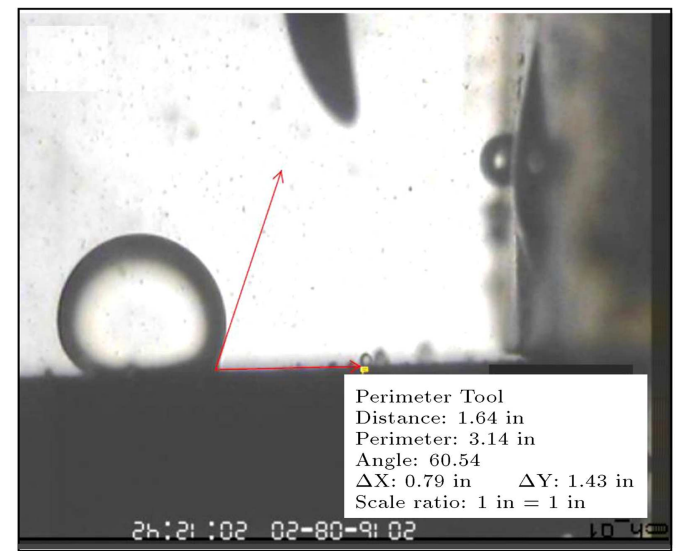

(b)

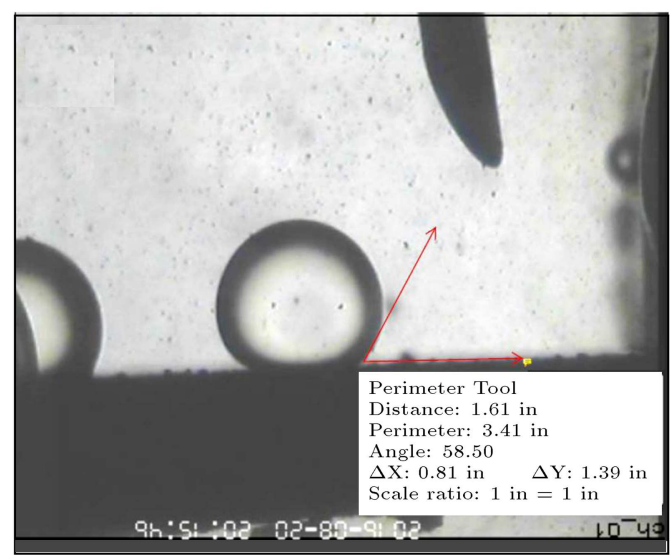

(d)

Figure 7. Contact angle between (a) water droplet and carbonate rock reservoir as reference sample, (b) water droplet and stone reservoir with a layer of $70 \% \mathrm{SWCNT} / \mathrm{SiO}_{2}$ nanohybrid, (c) water droplet and stone reservoir with a layer of $70 \%$ nanoporous graphene/silica nanohybrid (Method 1), and (d) water droplet and stone reservoir with a layer of $70 \%$ nanoporous graphene/silica (Method 2) nanohybrid similar to the method that was described in [24] with slight modification.

Figure 7 , the contact angles of (a) water droplet and stone reservoir, (b) water droplet and stone reservoir with a layer of $\mathrm{SWCNT} / \mathrm{SiO}_{2}$ nanohybrid, (c) water droplet and stone reservoir with a layer of $70 \%$ nanoporous graphene/ $\mathrm{SiO}_{2}$ nanohybrid (Method 1), and (d) water droplet and stone reservoir with a layer of $70 \%$ nanoporous graphene/ $\mathrm{SiO}_{2}$ nanohybrid (Method 2 ) are $143.47,68.89,60.54$, and 58.50, respectively. As can be seen, the $70 \%$ nanoporous graphene/ $\mathrm{SiO}_{2}$ nanohybrid (Method 2) has the least contact angle amount in comparison to the other samples, and it represents more hydrophilicity and better alteration of the wettability of carbonate reservoir rock from oil-wet to water-wet. We suppose that the layer structure of nanoporous graphene can better spread on stone reservoir in comparison to single-walled carbon nanotubes. Therefore, $70 \%$ nanoporous graphene $/ \mathrm{SiO}_{2}$ nanohybrid (Method 2) is more effective in the alteration of stone reservoir wettability from oil-wet to water-wet, and the related Pickering emulsion can be used for Chemical Enhanced Oil Recovery (C-EOR).

According to the interfacial tension results presented in Figure 8, the related amounts of injection droplets of (a) water, (b) $70 \% \mathrm{SWCNT} / \mathrm{SiO}_{2}$ nanohybrid, (c) $70 \%$ nanoporous graphene/ $\mathrm{SiO}_{2}$ nanohybrid (Method 1), and (d) 70\% nanoporous graphene/ $\mathrm{SiO}_{2}$ nanohybrid (Method 2) are $53.90 \mathrm{mN} / \mathrm{m}, 31.21 \mathrm{mN} / \mathrm{m}$, $30.04 \mathrm{mN} / \mathrm{m}$, and $29.82 \mathrm{mN} / \mathrm{m}$, respectively. The maximum amount is related to the injection of water, and the minimum amount is related to the injection of nanofluid of $70 \%$ nanoporous graphene $/ \mathrm{SiO}_{2}$ nanohybrid (Method 2). This result indicates the preference of $70 \%$ nanoporous graphene $/ \mathrm{SiO}_{2}$ nanohybrid (Method 2) for decreasing the interfacial tension in comparison to the other samples. Therefore, $70 \%$ nanoporous graphene/ $\mathrm{SiO}_{2}$ nanohybrid (Method 2) Pickering emulsion can be used for Chemical Enhanced Oil Recovery (C-EOR). 


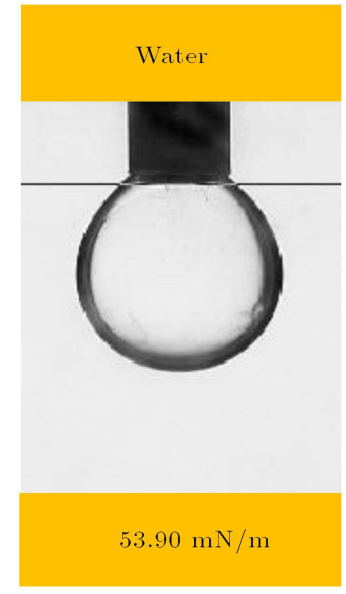

(a)

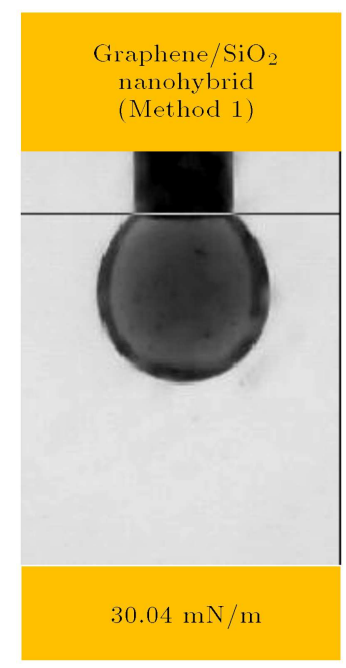

(c)

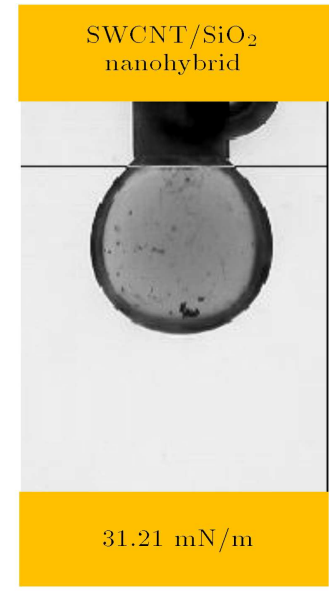

(b)

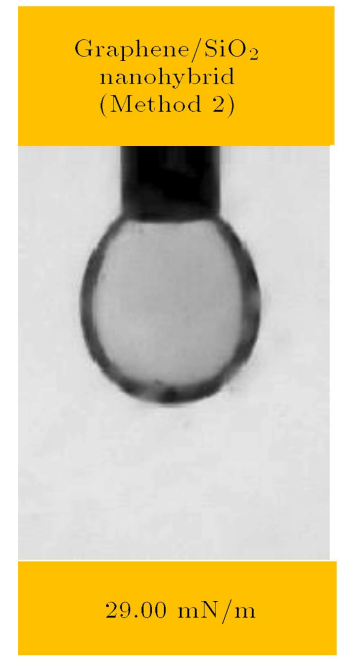

(d)
Figure 8. Interfacial tension determination of (a) water, (b) $70 \% \mathrm{SWCNT} / \mathrm{SiO}_{2}$ nanohybrid, (c) $70 \%$ nanoporous graphene/ $\mathrm{SiO}_{2}$ nanohybrid (Method 1), and (d) $70 \%$ nanoporous graphene/ $\mathrm{SiO}_{2}$ nanohybrid (Method 2) similar to the method that was described in [24] with slightly modification.

\section{Conclusion}

In this paper, Single-Walled Carbon nanotubes (SWCNTs) and nanoporous graphene nanohybrids with $\mathrm{SiO}_{2}$ nanoparticles were synthesized with different weight percentages. The related nanohybrids Pickering emulsions were prepared with $n$-octane as oil model, suitable anionic surfactant (such as SDBS) and 2Propanol as alcoholic co-surfactant at $\mathrm{pH}=7$, and ambient temperature with distilled water. Stability of the mentioned Pickering emulsions was controlled for one month. Emulsion phase morphology was investigated with optical microscopic image. Evaluation results demonstrated that the best samples are $70 \%$ SWCNT $/ \mathrm{SiO}_{2}$ (Method 1) and $70 \%$ nanoporous graphene $/ \mathrm{SiO}_{2}$ nanohybrids (both methods). Contact angle measurement results showed that the $70 \%$ nanoporous graphene/ $\mathrm{SiO}_{2}$ nanohybrid (Method 2) is more effective in the improvement of the stone reservoir wettability alteration from oil-wet to waterwet. Interfacial tension results indicate that the maximum amount is related to the injection of water, and the minimum amount is related to the injection of nanofluid of $70 \%$ nanoporous graphene $/ \mathrm{SiO}_{2}$ nanohybrid (Method 2). This result indicates the preference of $70 \%$ nanoporous graphene $/ \mathrm{SiO}_{2}$ nanohybrid (Method 2 ) for decreasing the interfacial tension in comparison to the other samples. Therefore, $70 \%$ nanoporous graphene/ $\mathrm{SiO}_{2}$ nanohybrid (Method 2) Pickering emulsion can be used for Chemical Enhanced Oil Recovery (C-EOR).

\section{Acknowledgment}

The authors are grateful to Research Institute of Petroleum Industry for its support of this research.

\section{References}

1. Duncan, G. "Enhanced recovery engineering", Pt.1. World Oil, 215, p. 97 (1994).

2. Mingyi, T., Tao, W., Xiaoyang, Xu., Zhang, L. and Wu, F. "Factors that affect the stability, type and morphology of Pickering emulsion stabilized by silver nanoparticles/graphene oxide nanocomposites", Materials Research Bulletin, 60, pp. 118-129 (2014).

3. Shen, M. and Resasco, D.E. "Emulsions stabilized by carbon nanotube-silica nanohybrids", Langmuir, 25, p. 10843 (2009).

4. Pilar Ruiz, M., Faria, J., Shen, M., Teerawit, P. and Resasco, D.E. "Nanostructured carbon-metal oxide hybrids as amphiphilic emulsion catalysts", ChemSusChem, 4, pp. 964-974 (2011).

5. Zhang, N.N., Qiu, H.X., Liu, Y., Wang, W., Li, Y., Wang, X.D. and Gao, J.P. "Fabrication of gold nanoparticle/graphene oxide nanocomposites and their excellent catalytic performance", J. Mater. Chem., 21, pp. 11080-11083 (2011).

6. Kim, J.D., Palani, T., Kumar, M.R., Lee, S.W. and Choi, H.C. "Preparation of reusable $\mathrm{Ag}$ decorated graphene oxide catalysts for decarboxylative cycloaddition", J. Mater. Chem., 22, pp. 20665-20670 (2012).

7. Giovanni, M., Poh, H.L., Ambrosi, A., Zhao, G.J., Sofer, Z., Sanek, F., Khezri, B., Webster, R.D. and Pumera, M. "Noble metal (Pd, Ru, Rh, Pt, $\mathrm{Au}, \mathrm{Ag}$ ) doped graphene hybrids for electrocatalysis, Nanoscale", Nanoscale, 4, pp. 5002-5008 (2012).

8. Chen, X.M., Wu, G.H., Chen, J.M., Chen, X., Xie, Z.X. and Wang, X.R. "Synthesis of "clean" and welldispersive $\mathrm{Pd}$ nanoparticles with excellent electrocatalytic property on graphene oxide", J. Am. Chem. Soc., 133, pp. 3693-3695 (2011). 
9. Tang, M., Wu, T., Xu, X., Zhang, L. and Wu, F. "Factors that affect the stability, type and morphology of Pickering emulsion stabilized by silver nanoparticles/graphene oxide nanocomposites", Mater. Res. Bull., 60, pp. 118-129 (2014).

10. Lightcap, I.V., Kosel, T.H. and Kamat, P.V. "Anchoring semiconductor and metal nanoparticles on a two-dimensional catalyst mat. Storing and shuttling electrons with reduced graphene oxide", Nano Let., 10, pp. $577-583$ (2010).

11. Goncalves, G., Marques, P.A.A.P., Granadeiro, C.M., Nogueira, H.I.S. and Singh, M.K. "Surface modification of graphene nanosheets with gold nanoparticles: The role of oxygen moieties at graphene surface on gold nucleation and growth", J. Gracio, Chem. Mater., 21, pp. 4796-4802 (2009).

12. Si, Y. and Samulski, E.T. "Exfoliated graphene separated by platinum nanoparticles", Chem. Mater., 20, pp. 6792-6797 (2008).

13. Scheuermann, G.M., Rumi, L., Steurer, P., Bannwarth, W. and Mülhaupt, R. "Palladium nanoparticles on graphite oxide and its functionalized graphene derivatives as highly active catalysts for the SuzukiMiyaura coupling reaction", J. Am. Chem. Soc., 131, pp. 8262-8270 (2009).

14. Park, S. and Ruoff, R.S. "Chemical methods for the production of graphened", Nat. Nanotechnol., 4, pp. 217-224 (2009).

15. Segal, M. "Selling graphene by the ton", Nat Nanotechnol., 4, pp. 612-614 (2009).

16. Kou, L. and Gao, C. "Making silica nanoparticlecovered graphene oxide nanohybrids as general building blocks for large-area superhydrophilic coatings", Nanoscale, 3, pp. 519-528 (2011).

17. Kim, J.Y., Cote, L.J., Kim, F., Yuan, W., Shull, K.R. and Huang, J.X. "Graphene oxide sheets at interfaces", J. Am. Chem. Soc., 132, pp. 8180-8186 (2010).

18. Tan, R., Li, C.Y., Luo, J.Q., Kong, Y., Zheng, W.G. and Yin, D.H. "An effective heterogeneous L-proline catalyst for the direct asymmetric aldol reaction using graphene oxide as support", J. Catal., 298, pp. 138147 (2013).

19. Mayavan, S., Jang, H.S., Lee, M.J., Choi, S.H. and Choi, S.M. "Enhancing the catalytic activity of Pt nanoparticles using poly sodium styrene sulfonate stabilized graphene supports for methanol oxidation", J. Mater. Chem. A., 1, pp. 3489-3494 (2013).

20. Muhammad, S., Chandra, V., Kemp, K.C. and Kim, K.S. "Synthesis of N-doped microporous carbon via chemical activation of polyindole-modified graphene oxide sheets for selective carbon dioxide adsorption", Nanotechnol., 24, pp. 255702-255709 (2013).

21. Mi, X., Huang, G.B., Xie, W.S., Wang, W., Liu, Y. and Gao, J.P. "Preparation of graphene oxide aerogel and its adsorption for $\mathrm{Cu}^{2+}$ ions", Carbon, 50, pp. 4856-4864 (2012).
22. Liu, Y., Ma, J.K., Wu, T., Wang, X.R., Huang, G.B. and Liu, Y. "A cost effective reduced graphene oxidecoated polyurethane sponge as a highly efficient and reusable oil-absorbent", ACS Appl. Mater. Interfaces., 5, pp. 10018-10026 (2013).

23. Rao, C.N.R., Biswas, K., Subrahmanyam, K.S. and Govindaraj, A. "Graphene, the new nanocarbon", $J$. Mater. Chem., 19, pp. 2457-2469 (2009).

24. Ershadi, M., Alaei, M., Rashidi, A.M., Ramazani, A. and Khosravani, S. "Carbonate and sandstone reservoirs wettability improvement without using surfactants for Chemical Enhanced Oil Recovery (C-EOR)", Fuel., 153, pp. 408-415 (2015).

25. Jabari Seresht, R., Jahanshahi, M., Rashidi, A.M. and Ghoreyshi, A.A. "Fabrication and evaluation of nonporous graphene by a unique spray pyrolysis method", Chem. Eng. Technol., 36, pp. 1-10 (2013).

26. Zhang, T., Davidson, D., Bryant, S.L. and Huh, C. "Nanoparticle-stabilized emulsions for applications in enhanced oil recovery", SPE Improved Oil Recovery Symposium, 24-28 April, Tulsa, Oklahoma, USA (2010).

27. Whitby, C.P. and Wanless, E.J. "Controlling Pickering emulsion destabilisation: A route to fabricating new materials by phase inversion", Materials, 9, pp. 626648 (2016).

\section{Biographies}

Mahsan AfzaliTabar completed her MSc (2012) and PhD degrees (2016) in Inorganic Chemistry under the supervision of Dr. Roya Ranjineh Khojasteh from Islamic Azad University, North Tehran Branch, Tehran, Iran, and Dr. Mahshad Alaei from Research Institute of Petrolum Industry (RIPI), Tehran, Iran.

Her PhD thesis is based on "Preparation and characterization of carbon nanostructures nanohybrids for the preparation of Pickering emulsions for Chemical Enhanced Oil Recovery (C-EOR)".

Mahshad Alaei is an Assistant Professor of Inorganic Chemistry and a member of scientific board of Nanotechnology Research Center of Research Institute of Petroleum Industry (RIPI), Tehran, Iran. Her main research fields are nanolubricant additives, nanocorrosion inhibitors, and homogenous nanocatalysts for heavy crude oil upgrading, nanophotocatalysts, and nanomaterials for C-EOR.

Roya Ranjineh Khojasteh completed her MSc (1995) and PhD (2002) in Inorganic Chemistry under the supervision of Professor Gholivand from the Science and Research Branch, Islamic Azad University, Tehran, Iran.

Her doctoral thesis was based on "Synthesis and applications of Organophosphorous compounds". Her 
current research interest focuses on the design of new chiral ligands, development of new complexes, the formation of stereocenters using new synthetic methodologies, catalytic reactions, and nanotechnology. She has published several research papers in well-reputed international journals. Presently, she is an Associate Professor (in 2003) at the North Tehran Branch, Islamic Azad University.

Freshteh Motiee is a PhD student of Applied Chemistry. She is an Assistant Professor of Applied Chemistry Department at Islamic Azad University, North Tehran North Branch. She is interested in rubber com- pounding and technology, synthesis of new ingredients for rubber industries, optimization of aging conditions of rubber and the structure-properties modelling of rubber compounds.

Ali Morad Rashidi is a Professor of Chemical Engineering at Nanotechnology Research Center, Research Institute of Petroleum Industry (RIPI), Tehran, Iran. His main research Interests include carbon nanostructures (mostly CNTs, CNF, and graphene based nanomaterials), nanocatalysts, nanoadsorbents and hybrid nanomaterials and their application in the field of chemical engineering. 